\title{
The Application of an Entropy Theory of Concentration to the Clayton Act
}

\author{
Michael O. Finkelstein* \\ Richard M. Friedberg***
}

I.

Section 7 of the Clayton Act prohibits mergers whose effect "may be substantially to lessen competition, or to tend to create a monopoly," in any line of commerce. ${ }^{1}$ In applying this Act, the Supreme Court has seemed to give judicial recognition to the economic view that "the relative size distribution of firms in particular markets is an important clue, often the single most important one, to the nature of the competitive process in them."' Both the Court and the Federal Trade Commission have come to rely increasingly on numerical measures of concentration in appraising the competitive character of an industry. ${ }^{3}$ A standard for measuring economic concentration has thus emerged as a first requirement of a rational anti-merger policy.

* Member of the New York Bar. B.A. 1955, LL.B. 1958, Harrard University.

** Assistant Professor of Physics, Columbia Úniversity. B.A. 1956, Harvard University; Ph.D. 1962, Columbia University.

We wish to thank the Walter E. Meyer Foundation for its generous support of this project. We are indebted to Elinor F. Finkelstein and to Stanley D. Robinson of the New York Bar for their critical reading of the manuscript.

1. 15 U.S.C. $\$ 18$ (1964). This article is concerned principally with horizontal mergers. Although conglomerate mergers are probably statistically the single most important type, the significant role which horizontal mergers continue to play may be gauged from the estimate that in the period 1959-196I more than one-third of all workers in firms absorbed by merger were involved in horizontal acquisitions. See U.S. BunEAU OF TIE CENSUS, AcQuistrions aNd Disposals of MANufacturing Facilmies (1959-1962); US. BunEau of miE Census, ANnual Survey of Manufactures (1962). For a recent statistical overview of the "record level" of merger activity by which 1,893 firms were acquired in 1965, see Federal Trade Commission, News Release, February 11, 1966.

2. Statement of Carl Kaysen, Hearings before the Subcommiltee on Antilrust and Monopoly of the Senate Judiciary Committee, 89th Cong., 1st Sess., pt. 2, at 543 (1965).

3. The leading cases are: United States v. Pabst Brewing Co., 384 U.S. 901 (1960); United States v. Von's Grocery Co., 384 U.S. 270 (1960); United States v. Continental Can Co., 378 U.S. 441 (1964); United States v. Aluminum Co. of Amcric, 377 U.S. 271 (1964); United States v. Philadelphia National Bank, 374 U.S. 321 (1963); Brown Shoe Co. v. United States, 370 U.S. 294 (1962).

The spectrum of firm sizes in an industry has also played a key role in government reports dealing with the merger problem and the level of competition. Sce, e.g., Nistri REPORT OF THE ATTORNEY GENERAI ON COMPETITION IN THE SYNTIUETIC RUDDER INDUSTIY (1963); FTC, Economic Ineuiry INTo Food MIARheting, Part II, THE Frozen Frutr, Juice and Vegetable Industry (1962) and Part III, The CaNind Fruit, Juice and VEGETABLE INDUSTRY (1965); FTC, ECONOMIC REPORT ON AIERGERS AND Vertical INTEGRATION IN THE CEMIENT INDUSTRY (1966). 
Measures of concentration are designed to reduce figures portraying the sizes of firms in a market into a single figure summarizing the degree of concentration of that market. This compression of data in. evitably results in the loss of certain information. The nature and significance of the loss depend on the type of summary, and the purpose for which the measure is used. There is, consequently, little right or wrong in the abstract about a measure of concentration; its "correctness" depends entirely on its context. ${ }^{4}$

In Clayton Act merger cases, lawyers and judges have generally relied on a measure of economic concentration known as the concentration ratio. The structure of this ratio is so simple and intuitively appealing that there has never been a satisfactory analysis of its utility for resolving antitrust issues. This omission has become increasingly important as the Court has come to rely more heavily on economic statistics interpreted through concentration ratios. Other measures of concentration, however, have significantly different attributes which may impel different results. In the absence of analysis, it cannot be assumed that the concentration ratio or any other measure will rightly serve the policies of the antitrust laws.

In this article we examine various methods of measuring concentration for Clayton Act purposes. We suggest that none of the methods now in use fulfills the requirements of the law. Rather, we propose a new measure of economic concentration, intended to express more accurately the relationship between market structure and competition which is crucial to the Clayton Act merger cases. We have called this an entropy measure of concentration because it formally resembles a measure of entropy-the degree of molecular disorder in a gaswhich is used in a branch of physics known as the kinetic theory of gases. Perhaps this formal resemblance reflects some underlying similarity between molecular and economic disorder. In this article, how* ever, we view the connection with physics only as a coincidence which furnishes a name. The justification of the measure presented here in no way depends on any deeper substantive connection.

The entropy measure of concentration is derived from theoretical considerations relating the number and sizes of firms in a market to

4. If, for example, sizes of individual firms are expressed as percentages of markct, a firm which has ten customers out of a market of one hundred, and a firm which has onc hundred customers out of a market of one thousand, will both be labeled 10 per cent firms. There is nothing wrong with this formulation if the significant fact is relative size in a market. The percentage measure is misleading only if absolute size is more important; if it is, the second firm should be treated as ten times larger than the first, rather than its equal. 
the degree of competition anticipated for that market. This derivation requires a more sophisticated mathematical argument than is common in the law or is necessary to understand other methods of measurement which lack theoretical underpinning. The mathematical techniques by which this argument is expressed may be regarded by some lawyers and judges with trepidation-as an appeal to some ultima thule of the mind. From the traditional legal point of view mathematical analysis may seem alien in spirit, without compelling history and without those congenial guides of common sense and intuition upon which so much of legal decision depends. In part this is a problem of familiarity. The symbolism may be more bafling and the chains of reasoning more involved, but complex mathematical methods are not essentially different from their simpler counterparts-such as percentages-which have enjoyed a wide use in the law. We venture beyond elementary methods because developments in the merger law have outrun them. The result of this effort is, we believe, an instrument of measurement better suited than existing measures to the judgments required by the Clayton Act.

II.

\section{Concentration Ratio Tests-Horizontal Mergers}

The measure of economic concentration most frequently used by lawyers and economists in the horizontal merger cases is the concentration ratio. This is a percentage figure representing the aggregate market share of a given number of leading firms in an industry. Thus if the first two firms in an industry control, respectively, 30 and 10 per cent of the market, the two-firm concentration ratio for that market is 40 per cent. Economic trends and individual mergers have been assessed in terms of these ratios and by considering changes in the number of firms in the relevant lines of commerce. The concentration ratio most commonly used by economists is the aggregate market percentage of the top four firms, although concentration ratios based on different numbers of firms are not uncommon. For purposes of illustration, we employ a four-firm ratio.

5. For studies involving the application of concentration ratios to various industries, see, e.g., U.S. Bureau of the Census, Concentration Ratios is Minufacturusc in: DUSTRrES (1963); Shepherd, Trends of Concentration in American Manufacturing Industries, 1947-1958, 46 REv. OF ECON. \& STATISTICS 200 (1964) and articles cited therein at note 2. For a discussion of some of the limitations of concentration ratios and other measures see National BuREAU OF ECONOMIG RESEArCh, BUSLNESS CONCENTRATION AND PRICE Policy (1955); Adelman, The Measurement of Industrial Concentration, 33 REv. OF ECON. \& STATISTIES 269 (1951). 
We begin the analysis by observing that the value of the four-firm ratio changes only when any of the four firms grows or declines relative to any firm in the industry outside the top four. The ratio does not reflect changes in the market shares of the four leading firms when their aggregate market share remains unchanged, or changes involving the market share of the remaining firms when their aggregate market share remains unchanged. Yet these changes can be of considerable economic importance. Two industries may show the same ratio, even though in the first the top four firms are of equal size, while one huge firm dominates the second. Similarly, the remaining market may be divided among few or many firms. The competitive behavior of firms in a market with eight equal firms, usually considered an oligopoly, will probably differ greatly from that in a market with a hundred firms even if in both cases the first four firms have a 50 per cent share.

An additional defect of the concentration ratio is that the number of included firms is altogether arbitrary. A gain by firm five at the expense of firm ten would not change a four-firm ratio but would be reflected if five firms were included. But there is no reason to suppose that the fate of firm four should be given full significance and that of firm five none. Whatever number of firms included in the concentration ratio, we are led to some such unreasonable hypothesis, since there is no argument by which any particular number of firms is to be preferred. Because it thus reflects only a limited, arbitrarily chosen class of size changes, the concentration ratio is a poor method for measuring trends in concentration.

The use of a concentration ratio to measure a single change in firm sizes resulting from an acquisition presents other difficulties. First, as the Court has used it, the ratio does not accurately reflect the decrease in competition resulting from an acquisition. To illustrate this assume a line of commerce with ten competing firms each with 10 per cent of the market. One firm turns predator and acquires, successively, the other nine. How should the significance of these acquisitions be measured? The Court has approached problems of this type by computing both the absolute increase (i.e., the number of percentage points added) and the percentage increase in the ratio. In our example, if the concentration ratio is defined by the percentage share of the predator firm, then every acquisition increases the ratio by the same absolute amount-ten percentage points-which becomes a smaller percentage increase of the ratio as the size of the leading firm grows. As a result of the first acquisition the ratio increases from 10 to 20 
per cent, a 100 per cent increase. When our predator firm acquires its last rival, the ratio increases from 90 to 100 per cent, an increase of only 11 per cent.

This result, however, is inconsistent with the likely effect of these acquisitions on competition. The first acquisition which leaves eight competitors in the field surely hurts competition less than the last, which eliminates the final competitor. The ratio test, in effect, rewards bigness; the larger the acquiring firm the smaller the percentage change resulting from an acquisition. Whatever the economic truth may be, it is clear that the change in the concentration ratio fails to give effect to the teaching of the Court in several recent cases that the greater the degree of concentration the smaller the permissible increase. ${ }^{\circ}$

A second basic difficulty arises in connection with the number of firms included in the ratio. When used to reflect the result of a single acquisition, the ratio must be computed from the aggregate market share of the acquiring firm and of the firms larger than it. The acquiring firm must be included; otherwise the ratio will not change as a result of the acquisition. Firms smaller than the acquiring firm must be excluded, or an acquisition by the acquiring firm will not be distinguishable from an acquisition by one of the included smaller firms.

As a result, the number of included firms must vary from case to case making it impossible to use a predetermined number for measuring all acquisitions. Since comparisons cannot validly be drawn be-

6. In United States v. Philadelphia National Bank, 374 U.S. 321 (1963), the Court invalidated a merger of the second and third largest banks in the Philadelplina area. The defendants argued that there would be no increase in concentration if consideration were restricted to the first three banks before the merger. In purportedly answering this argument the Court established, in a footnote, an important principle:

If this argument were valid, then once a market had become unduly concentrated, further concentration would be legally privileged. On the contrary, if concentration is already great, the importance of preventing even slight increases in concentration and so preserving the possibility of eventual deconcentration is correspondingly great. Id. at $365 \mathrm{n} .42$.

The footnote in Philadelphia Bank became the basis for decision in United States v. Aluminum Company of America, 377 U.S. 271, 279 (1964). In this case the Court invalidated the acquisition by Alcos of the stock and assets of Rome Cable, a corporation which produced various wire and cable products and accessories. The Court determined that bare and insulated aluminum conductor was the relciant line of commerce. In this market Alcoa was the leader, with a market share of 27.8 per cent, while Rome was ninth with 1.3 per cent. The Court found that in this market the first two companies controlled 50 per cent of the market; the first five companies 76 per cont; and the first nine companies 95.7 per cent. It thus concluded that "the line of commerce showed highly concentrated markets, dominated by a few companies but served also by a small, though diminishing group of independents." The case was then decided on the authority of the Philadelphia Bank footnote. 
tween concentration ratios based on differing numbers of firms, comparability of result is destroyed and with it the possibility of stare decisis. ${ }^{7}$

The lack of comparability may affect the issues considered by a court. In the Alcoa case, for example, two lines of commerce were asserted by the Government-insulated aluminum conductor and a wider line of insulated and bare aluminum conductor. In the insulated line Alcoa was third with 11.6 per cent of market. Rome, the firm it acquired, held 4.7 per cent. In the wider line of aluminum conductor Alcoa was first with 27.8 per cent of market, while Rome held 1.3 per cent. In which proposed line of commerce was the merger more significant? In the absence of a measure leading to comparable results for both mergers, the Supreme Court rested its decision on the effect of the acquisition in the wider line. The merger probably appeared worse in that setting since it involved the leader of an industry. The Court thus assumed that insulated and bare aluminum properly constituted a single line of commerce. As the dissenters pointed out, this was a dubious proposition for which there was no evidence in the record. In fact the issue was irrelevant since, as we shall demonstrate, the merger's anti-competitive effects were probably more significant in the narrower than in the wider market. ${ }^{\mathrm{s}}$

The concentration ratio thus has fundamental defects when used to measure either economic trends or the effects of a single horizontal

7. To illustrate this, assume that the leading firm in an industry holds 50 per cent of the market and acquires the second firm which holds 25 per cent. The concentration ratio measured by the leading firm has increased from 50 to 75 per cent. Now assume that the first two firms hold 25 and 25 per cent respectively and the second firm acquires a third firm which also holds 25 per cent. In this case the two-firm concentration ratio rises from 50 to 75 per cent just as the single-firm concentration ratio did in the first casc; yet the two mergers are statistically very different.

8. Comparisons were also important in United States v. Manufacturers Hanover, 240 F. Supp. 867 (S.D.N.Y. 1965), where the Government claimed that the merger between Manufacturers Trust Co. and The Hanover Bank should be invalidated on the basis of the statistical evidence alone in light of Philadelphia Bank. The Court had found in Philadelphia Bank that the merger would result in a significant increase in concentration. It based this conclusion on the fact that before the merger the first and sccond banks controlled 44 per cent of the market, and that if the merger were permitted the first and second banks (the merging banks being two and three) would control 59 per cent of the market. "Plainly," the Court concluded, "we think this increase of more than $33 \%$ in concentration must be regarded as significant." Since the merger in Philadelphia Banl involved the second and third banks in the area, the concentration ratio could consist of the aggregate shares of not more than the first two banks. In Manufacturers Hanover, however, the merger was between banks five and eight in the New York City arca. The concentration ratio for this market would necessarily include not less than five banks. Consequently a comparison of the statistics in these cases using a concentration ratio was not possible. Instead the district court concluded that the merger in Philadelphia Banls was worse than in Manufacturers Hanover because the relative size of the merged banks was greater in the first case than in the second. While this comparison is rclevant, it does not take into account significant information from the remainder of the market. 
merger. In measuring trends its value depends on a narrow, arbitrarily chosen class of economic changes which of necessity tell only part of the story. In measuring the effects of a single acquisition it either overstates their significance when the market is concentrated, or understates their significance when the market is not concentrated, or both. Moreover, the results must be cast in terms of such limited comparability as virtually to destroy the usefulness of the measure as a unifying index of the significance of acquisitions.

\section{Percentage Foreclosure Tests-Vertical Mergers}

Similar problems appear in measuring the significance of vertical mergers. Vertical integration may be accomplished either permanently by merger or temporarily by contract. In the first case legality under the Clayton Act turns on the applicability of Section 7, and in the second on the applicability of Section 3, which prohibits exclusive arrangements, such as requirements contracts, where their result "may be to substantially lessen competition or tend to create a monopoly in any line of commerce."9

Although Sections 3 and 7 use similar language, their governing principles are not identical. Under Section 3, as a result of the Standard Stations decision, ${ }^{10}$ a determination that a requirements contract, for example, is likely to result in a substantial lessening of competition depends primarily on the degree of market foreclosure resulting from the contract. If foreclosure is quantitatively substantial, a violation of Section 3 would be established. In Standard Stations the Court found requirements contracts illegal which foreclosed 6.7 per cent of an extremely large market.

Regardless of any differences of interpretation, the percentage of foreclosure is undoubtedly relevant in determining whether there has been a substantial lessening of competition, just as the combined percentage of market of the merging firms is relevant when horizontal mergers are considered. To the extent of the foreclosure, competitive firms are cut off from customers and vice versa. But to determine whether the foreclosure has been substantial a court must consider the degree of concen-

9. 15 U.S.C. $\$ 14$ (1964).

10. Standard Oil Co. of California v. United States, 337 U.S. 293 (1919). The quantitative substantiality approach to vertical mergers was in evidence when the FTC recently anounced that it would attack vertical acquisitions in the cement industry where the acquired company was a ready-mixed concrete firm ranked among the first four non-integrated producers in any metropolitan market, or was a cement consumer purchasing 50,000 or more barrels of cement annually. FTC, Commission Enforcement Policy with Respect to Vertical Mergers in the Cement Industry, I Trade Rec. Rep. I 4510. 
tration (and foreclosure) in the remainder of the market, a factor which the percentage foreclosure test does not take into account. In the proposed Bethlehem-Youngstown merger one vertical aspect of the case arose from the fact that Youngstown was an independent producer of rope wire, a product used in the manufacture of wire rope by Bethlehem among others. The threatened foreclosure was approximately 10 per cent. In holding this substantial, the court, in United States v. Bethlehem Steel Corp., ${ }^{11}$ relied on the additional fact that there were only five other independent producers of rope wire. It found the percentage foreclosure significant in light of the high degree of concentration in the remainder of the market.

There is another disadvantage to the percentage foreclosure test. Although theoretically measuring the same thing - a substantial lessening of competition-the percentage foreclosure test for vertical integrations and the concentration ratio test for horizontal acquisitions do not lead to results which can be compared. In justifying its conclusion in Philadelphia Bank that an increase of 33 per cent in concentration was substantial, the Court cited Standard Stations and other vertical integration cases where the percentage foreclosure was less than 33 per cent. The comparison however was misplaced. The percentage foreclosure test measures the degree to which the market has shrunk for the remaining competitive firms. The change in the concentration ratio measures the growth in the size of a firm. Although in both cases results may be expressed in percentage terms, they measure different things. Thus a 5 per cent foreclosure is not analogous to a 5 per cent increase in a concentration ratio. A lack of comparability thus appears inherent in tests dependent on concentration ratios and between such tests and percentage foreclosure tests.

It may be argued that the failure of these measures to take account of economically significant facts may be remedied by considering those facts on a separate basis. For example, if concentration ratios do not reflect changes in the number of firms, those changes can be stated independently. But this does not solve the problem. If significant matters are considered separately, there is no way of deciding how their effects should be combined and, if conflicting in their impetus, how that conflict should be resolved. ${ }^{12}$ The solution requires a unitary

11. 168 F. Supp. 576, 611-13 (S.D.N.Y. 1958).

12. A conflict of factors was present in United States v. Von's Grocery Co., 384 U.S. 270 (1966), where the district court found that concentration had decreascd bccausc the aggregate percentage of the top firms had declined, while the Supreme Court concluded au contraire that concentration had increased because the number of firms 
measure which combines the effect of all relevant factors and which expresses that result in a form which is useful for the economic judgments required of a court.

\section{Alternative Legal Rules}

Some lawyers and economists have suggested that a unitary measure could be created by pruning the statistical tree to a single branch. They have proposed that a merger should be deemed prima facie unlawful if the market shares of the merged firms exceed a given percentage. ${ }^{13} \mathrm{Few}$ commentators, however, have suggested that a merger which produces a firm with less than such a percentage should be conclusively valid. It is more usual to find the opinion that in such cases an examination of all factors is required. This reservation severely limits the usefulness of the rules since important cases frequently involve small percentages. ${ }^{14}$

had declined. Id. at 273 n.3. Neither court attempted to reach a conclusion based on a weighing of both sets of factors.

13. See, e.g., Bork, The Rule of Reason and the Per Se Concept: Price Fixing and Market Division II, 75 YaLE L.J. 377 (1966); KAysen \& TuRner, ANtrtsust Policy 133 (1959); Stigler, Mergers and Preventive Antitrust Policy, 104 U. PA. L. REv. 176 (1955). Professor Stigler, for example, would establish presumptions whereby mergers which create a firm with less than 5 to 10 per cent of the market would be sanctioncd while mergers which created a firm with more than 20 per cent would be disapproved. In between, legality would turn on other factors. Stigler, supra at 182.

The Federal Trade Commission recently announced that mergers by retail food chains or voluntary and cooperative groups of food retailers which created an enterprise with a sales volume in excess of $\$ 500$ million raised "sufficient questions regarding their legal status to warrant attention and consideration by the Commission . . . The Commission added, however, that lesser mergers could also pose a threat to competition and that such a threat would be present whenever leaders who were direct competitors in metropolitan markets sought to merge. FTC, Commission Enforcement Policy wilh Respect to Mergers in Food Distribution Industries, 1 TRADE REG. REP. I 4520.

14. Two recent Supreme Court decisions are notable examples. In United States v. Von's Grocery Company, 384 U.S. 270 (1966), the Court held that the acquisition in 1960 by Von's Grocery Company of Shopping Bag Food Stores, both large retail supermarket chains in Los Angeles, violated Section 7. Though even after the merger Von's controlled only 7.5 per cent of the Los Angeles grocery market, the Court concluded that the acquisition was illegal because both Von's and Shopping Bag were succesful and expanding companies and because the relevant market, though not jet concentrated, was "characterized by a long and continuous trend toward fewer and fewer competitors." The Court cited facts showing that the number of single store owners had declined and that the share of chains had increased as a result of acquisitions which were continuing at a rapid rate. This was, the Court felt, the very sort of trend Congress had declared "must be arrested."

In the second case, United States v. Pabst Brewing Company, 384 U.S. 901 (1960), the Court reversed a dismissal of the Government's action against the acquisition by Pabst Brewing Company of Blatz' Brewing Company, holding that the Government's cvidence was "amply sufficient" to show a violation of Section 7. At the opening of 1958, the year of the merger, Pabst was the tenth largest brewer in the country and Blatz the eighteenth. The acquisition made Pabst the fifth largest brewer with 4.49 per cent of total industry sales. By 1961, three years after the merger, Pabst's share of the national beer market was still only 5.83 per cent.

Under a rule such as Stigler's, see note 13 supra, the Court would have approved the mergers in both Von's and Pabst since the firms resulting from both mergers had less than 10 per cent of the market. 
The critical point in rules of this type is that they consign to irrelevance most of the factors which the Court has held important in deciding Clayton Act cases. They focus instead on a single element, the size of the merged firms. Consequently, whatever the percentage selected as the determining point of illegality, it is easy to construct examples illustrating the perversity of result which would follow the faithful application of any such rule. And it is the coup de grace for such proposals that they afford no way of measuring the trends in concentration, which have played such a large role in these cases.

Professor Bok of Harvard has proposed a more discriminating set of rules. He has suggested that the prohibitions of Section 7 be applied to any acquisition "resulting in an appreciable increase in the superiority of the leader's size over the margin of leadership which he enjoyed in the base period," and he has urged that any increase of more than a few percentage points should be viewed as "appreciable." 15 With respect to acquisitions by a firm other than the leader, Professor Bok offers a rule based on the concentration ratio of up to eight firms. If this ratio shows an increase of more than seven to eight percentage points from a base period, the merger should be prohibited because the industry has demonstrated a tendency to oligopoly which the statute was designed to arrest. ${ }^{16}$

Apart from the arbitrary nature of the particular percentages chosen, the principal problem with this set of rules is that they do not depend on the degree of economic concentration in the industry. This is important because the greater the concentration in a market the smaller the legally permissible increase in the leader's share or that of any number of leading firms.

Professor Bok's reliance on the aggregate market share of the leading firms (up to eight) involves the use of the familiar concentration ratio, and is subject to the objections already discussed. He attempts to meet at least one of these objections by claiming that changes in the number of firms should not be viewed as significant since the presence of marginal firms has little effect on competition. Clearly the Court thinks otherwise-as evidenced by the stress placed on the total number of firms in an industry in the recent Von's and Pabst decisions. ${ }^{17}$ There appears to be no legal justification for considering less than

15. See Bok, Section 7 of the Clayton Act and the Merging of Law and Economics, 74 HARv. L. REv. 226, 308 (1960).

16. Id. at 313 .

17. See note 14 supra. Of course, defendants are still free to prove if they can that disappearing firms were in fact marginal and consequently not significant for competition. 
all the available information concerning the number and relative sizes of firms in a line of commerce. The failure of Professor Bok's concentration ratio to take such facts into account is a shortcoming which reflects the general limitations of this class of measures.

\section{Econometric Methods}

In studying the distribution of wealth in a population economists have frequently used indices based on the average difference in wealth of its members. Differing functions have dressed this fundamental variable in a number of related fashions. ${ }^{18}$

The earliest method, developed by M. O. Lorenz in 1905, measures distribution of income in a population by plotting the cumulated percentage of the population against the cumulated percentage of wealth or income of that population. ${ }^{10}$ The resulting "Lorenz" curve is a straight diagonal if the distribution is equal and becomes more bowed as concentration increases.

The curve was given a more useful, numerical expression in 1912 by Corrado Gini. Gini proposed an index of concentration based on the ratio of the area between the Lorenz curve and the diagonal line of equal distribution divided by the total area under the diagonal. .0 Thus as the distribution of firm sizes moves from equality to inequality the ratio moves from zero to one. This ratio, called the Gini coefficient, is a function of the average difference of market shares of every possible pair of firms in the industry. It has been widely used by economists to measure what is commonly called relative concentration-the degree to which firm sizes differ. ${ }^{21}$ But the Gini coefficient does not measure the degree of absolute concentration-the extent to which economic power has gravitated into a few hands. It is zero whether an industry is divided among two or a hundred firms, so long as the division is equal. In general the coefficent will not change as a result of a change in the number of firms so long as the same percentage of firms controls the same percentage of market. This feature

18. The literature on this subject is collected in Singer, The Structure of Industrial Concentration Indexes, 10 ANTrTRust BuLL. 75 (1965).

19. Lorenz, Methods of Measuring the Concentration of Wealth, 70 Axr. Statistical. Assoc. J. 1 (1905).

20. Gini, Variabilia e Mutabilia 19 (1912).

21. If there are three firms, $A, B$, and $C$, the Gini cocfficient would be a function of the average of the differences $(A-B),(A-C)$ and $(B-C)$. WoytinskY, EArivics ANd Soctal. SECURITY IN THE UNITED STATES 251 (1943). More precisely, the Gini coclficient is equal to the sum of the differences between every pair of firms divided by two times the number of pairs of firms and this divided by the mean firm size. 
severely limits its usefulness as a tool for administering the antitrust laws. ${ }^{22}$

In fact any measure based on some average of the size differences between firms, while appropriate for measuring inequality of wealth, is unsuitable for measuring economic concentration. Since any such measure is based on differences in firm sizes, the entry or exit of a firm causes a dramatic change in value; the smaller the firm the greater the change. This is misleading because the presence or absence of a firm of negligible size does not significantly alter the degree of com. petition in the market. The difference is that in measuring the distribution of wealth we are concerned with the economic status of each individual, while in measuring competition we care only about the contribution of each firm to the level of competitive activity in the market as a whole. A firm which is too small to change this level should be ignored.

Other measures based on the sum of the squares of firm sizes have been proposed by Herfindahl and Niehans. ${ }^{23}$ These indices are superior to those discussed earlier in that they reflect both relative and absolute concentration and are not dramatically affected by the entry or exit of a firm of negligible size. Nevertheless they have other attributes which limit their usefulness for the law. Discussion of these problems, however, is best deferred until we have developed the entropy measure.

22. There is also no reason to suppose (although the fallacy is not apparent) that the Gini coefficient will correctly reflect changes in competition when the number of firms remains constant but their relative sizes change. The coefficient, for example, would treat a market of 4 firms with, respectively, 30 per cent, 30 per cent, 30 per cent, 10 per cent shares as having the same degree of concentration as a market whose four firms have 40 per cent, 20 per cent, 20 per cent, 20 per cent shares. While this may be a correct result there is nothing in Gini's theory to support the conclusion that these markets will probably be equally competitive.

23. Niehans, An Index of the Size of Industrial Establishments, 8 INr'L Econ. PAPERs 122 (1958); Herfindahl, Concentration in the Steel Industry, 1950 (Ph.D. disscrtation, Columbia University).

A method more recently suggested for appraising the degree of cconomic concentration is the standard measure of dispersion used by statisticians; this is the variance. It is defined as the sum of the squares of the deviations of items (e.g., percentages of market) from the arithmetic mean item (e.g., the arithmetic mean percentage) divided by the number of items (e.g., firms). It is apparent from this definition that the variance shares the limitations of the Gini coefficient. Like the Gini coefficient it does not measure absolute concentration, it changes dramatically with the appearance or disappearance of a small firm, and its measurement of relative concentration lacks any theorctical connection with the degree of competition.

For a discussion of the use of a variance which makes use of the logarithms of the sizes of firms see Hart \& Prais, The Analysis of Business Concentration: A Statistical Approach, $119 \mathrm{~J}$. of The Royal Statistical Soc'x ser. A, pt. I, at 150 (1956); Simon \& Bonini, The Size Distribution of Business Firms, 48 AM. ECON. REv. 607 (1958). The use of the log variance grew out of an effort to describe theoretically the basis of the distribution of firm sizes in a market-a problem which is unnecesary to solve for purposes of the antitrust laws. 
III.

In enacting the Geller-Kefauver amendment to Section 7 of the Clayton Act, Congress expressed concern with the social and political implications of concentration as well as with its economic effects. The relationship of bigness to the social and political ills which Congress sought to avoid is too generalized to lead to any particular measure of economic concentration. The relationship, however, between economic concentration and competition provides a more informative guide. Our effort will be to construct a measure which reflects the minimum competitive effort firms will believe necessary to hold their customers as a function of the number and sizes of competing firms.

We begin handicapped by the discouraging but inescapable fact that economic knowledge is not sufficiently advanced to enable us to predict the degree of competitive activity in a market even if all available economic evidence is considered. A fortiori, given information concerning solely the number and relative sizes of competing firms, we cannot say that such a market will be $x$ times more competitive than another with a different spectrum of firms. Yet the law, which presents the test of a "substantial lessening" of competition, requires that some such comparison be made.

How may the legal requirements be met within the limits of economic knowledge? There is no mathematical answer to this question. But certainly the numbers should play no more than the minimum role required by legal theory: they should formulate an economic statement which so reduces the scope of judgment as to determine the economic issue in the more extreme merger cases; in the closer cases the formulation should permit the numbers to be used as an important element together with other evidence. In addition, these economic statements should be cast in a form which permits comparisons between cases for purposes of stare decisis.

To fulfill these requirements, we propose a measure which translates any market into a market deemed to have an equivalent level of competitive activity but consisting solely of firms which have equal shares of market. We call such a market an equal-firm market. The effect of this translation is to reduce the problem of comparing states of market with differing numbers of unequal firms to the narrower problem of comparing equal-firm markets. The significance of the difference between equal-firm markets is not determined by a translation measure. Thus a market found equivalent to one with eight equal firms is not necesarily twice as competitive as a market equiva- 
lent to one with four equal firms. In fact, the meaning of the difference may vary from case to case. In closer cases, therefore, where the precise significance of the difference may become important, additional economic evidence will be essential to any decision.

The entropy measure we derive here is but one of a number of possible equal-firm translation measures of the type described. We show three independent derivations of the entropy measure and then consider some alternative translation measures.

\section{$A$ "Competitive Activities" Derivation}

We assume that it is possible to define certain activities of a firm as competitive and to speak of the degree to which a firm engages in such activities. Economists have described competitive activities as those which are determined by the market. In a perfectly competitive market all activities would be determined in the sense that market conditions would dictate every move. Conversely, in a perfect monopoly the controlling firm would have perfect freedom. The total of all competitive activities in a market may be thought of as the sum total of the competitive activities of each firm. If the firms in a market are all equal in size, each will contribute equally to the total. One may quarrel with these ideas, but the legal standard-"a substantial lessening of competition"-implies some conception of levels of competitive activity.

The foregoing conceptions can be expressed symbolically in the following way. If $f(n)$ is a function which describes the degree of competitive activity in a market consisting of $n$ equal firms, then the contribution of each firm to $f(n)$ is, since all are equal, $1 / n f(n)$. If, for example, there are four equal firms in a market then:

$$
f(4)=1 / 4 f(4)+1 / 4 f(4)+1 / 4 f(4)+1 / 4 f(4)
$$

We now make a far-reaching assumption: the minimum competitive effort a firm will undertake to retain its customers is a function solely of its percentage share of the market. Or, putting the same thought in a different way, the total competitive threat to a firm with a given percentage of market is constant no matter how the remaining market is divided. The underlying conception on which this assumption rests is that large firms constitute a proportionately greater threat than small firms and therefore the total competitive danger from a few large firms is equivalent to the total competitive danger from a greater number of proportionately smaller firms. This is admittedly a 
speculative assumption, but one which is at least not inconsistent with economic knowledge and which need only be generally and not precisely true in order to be useful.

If this assumption is accepted, then the contribution each firm makes to the total degree of competitive activity will be equal to the contribution that firm would make in a market otherwise identical but composed solely of firms equal to it in size. Thus the contribution of a 50 per cent firm in any market would be $1 / 2 f(2)$, the contribution of a 20 per cent firm would be $1 / 5 f(5)$ and in general the contribution of a firm which controlled $1 / n$th of a market would be $1 / n f(n)$. Denote the percentage share of the first firm by $1 / n_{1}$, the percentage share of the second firm by $1 / n_{2}$, etc. Then the total degree of competitive activity in the market is: $1 / n_{1} f\left(n_{1}\right)+1 / n_{2} f\left(n_{2}\right) \ldots 1 / n_{n} f\left(n_{n}\right)$.

We say that two markets are equivalent if they have the same total competitive activity. Given any market we seek to determine an equivalent equal-firm market. The entropy measure, which we denote by $C$, is the number of firms in this equivalent market.

It follows that:

$$
f(C)=1 / n_{1} f\left(n_{1}\right)+1 / n_{2} f\left(n_{2}\right) \ldots+1 / n_{n} f\left(n_{n}\right)
$$

When all firms are equal in size then:

$$
\begin{aligned}
f(C) & =f(n) \\
C & =n
\end{aligned}
$$

We now consider the problem of determining $f(n)$. We approach this by examining the way $f(n)$ should change as the market (or a fixed percentage segment of it) becomes divided among a larger number of equal firms.

What can be said about the way $f(n)$ should increase as $n$ increases? If a single firm controls an entire market, dividing it in two will obviously increase greatly the level of competitive activity since there will be some competition where none existed before. The increase in value of $f(n)$ should be correspondingly great. But if there are 100 equal firms dividing a market, the addition of a single firm will obviously be far less significant for competition; consequently the increase in $f(n)$ should be correspondingly smaller. These considerations lead us to adopt the general principle that as $n$ grows larger $f(n)$ should increase but at a diminishing rate. 
There are an infinite number of functions which have this characteristic. Economic theory or legal principle cannot be expected to determine a unique choice; arbitrary elements are inevitable in any conclusion.

The first decision is whether $f(n)$ should increase without bound as $n$ increases or whether there should be some upper value for $f(n)$ beyond which it never rises no matter how large $n$ becomes. In economic terms, the question raised is whether competition should be deemed to increase without limit as the number of firms increases. Or, stated differently, should small firms be viewed as significant contributors to competition? Our affirmative answer is suggested by the fact that in both Von's and Pabst the Court treated the disappearance of extremely small firms (those with less than .001 per cent of market) as significant for competition. In view of this, and in the absence of compelling economics to the contrary, we make a tentative decision in favor of functions which treat small firms as significant. We thus require that $f(n)$ should increase without bound (although at a diminishing rate) as $n$ increases. The opposite decision on this issue leads to an alternative measure which is considered in Part IV.

There are two important classes of functions which increase without bound at a diminishing rate. These differ in the importance they assign to small firms. In the first class are the "fractional power functions," so called because $n$ is raised to some fractional power between 0 and 1 . Thus $f(n)=n^{a / b}$. Probably the most familiar function of this type is $f(n)=n^{1 / 2}$ which means that $f(n)$ is equal to the square root of the number of equal firms.

The fractional power functions assign great significance to small firms. To see this consider the effect on $f(n)$ of doubling the number of firms in a market. A doubling yields the ratio $f(2 n) / f(n)=2^{a / b}$. The importance of this result is that $2^{a / b}$ is a constant independent of $n$. Thus if a fractional power function is used, doubling the number of firms will have the same proportional significance for competition regardless of the number of firms with which we started.

This result indicates that the fractional power functions probably overstate the significance of an increase in the number of firms. Doubling the number of firms in a market from 1 to 2 or from 2 to 4 should lead to a greater proportional increase in competition than doubling the number of firms from 1000 to 2000 . Generally it seems probable that a doubling in the number of firms should result in a diminishing proportional increase in $f(n)$ as $n$ increases. Since the 
fractional power functions assign equal significance to all doublings we reject this class of functions as candidates for $f(n)$.

The other class consists of the logarithmic functions. ${ }^{24}$ The simplest of these is $f(n)=\log (n)$ which means that $f(n)$ is simply equal to the logarithm of the number of equal firms. The logarithmic functions assign less significance to an increase in the number of firms than the fractional power functions. For example, if $\log \boldsymbol{n}$ is used, doubling the number of firms yields the ratio $(\log n+\log 2) / \log n$. As $n$ increases this ratio approaches 1 , which is consistent with the idea that a doubling becomes of diminished proportional significance as the number of firms increases. It is for this reason that we make a tentative choice in favor of the logarithmic functions. This choice, which is in substance one of policy, will in many cases favor the defendants since it assumes a slow reduction in competitive activity as the number of firms declines. ${ }^{25}$ The problem of deciding which logarithmic function to use remains unsolved since there are others more complex than $\log (n)$, such as $\log \log n$ and $(\log n)^{2}$, which also satisfy our requirements. But it is not at all clear which, if any, more complicated logarithmic function would be justified, and the simplicity of $\log n$ commends it as at least a leading candidate for $f(n)$. We shall see later that there are independent reasons for this choice.

Combining this result with our prior result yields the following:

$$
\begin{aligned}
\log C & =1 / n_{1} \log n_{1}+1 / n_{2} \log n_{2}+1 / n_{3} \log n_{3} \ldots+1 / n_{n} \log n_{n} \\
\log C & =\log \left(n_{1}^{1 / n_{1}} n_{2}^{1 / n_{2}} n_{3}^{1 / n_{3}} \ldots n_{n}^{1 / n_{n}}\right) \\
C & =n_{1}^{1{ }^{1 / m_{1}}} n_{2^{1 / n_{2}}} n_{3}^{1 / n_{3}} \ldots n_{n}^{1 / n_{n}}
\end{aligned}
$$

This expression for $C$ is what we propose as the entropy measure of concentration.

Before examining the characteristics of the entropy measure, there

24. We shall use the base 10 for logarithms. This means that the logarithm is defined as the power to which 10 must be raised to give the original number. In symbols, $10 \log ^{n}=n$. Thus $102=100 ; \log 100=2.103=1000 ; 10 \mathrm{~g} 1000=3$. $102=10$. $101.7=50 ; \log 50=1.7$. The last pair of equations is not exact. 101.t is really a trifle more than 50 , and 101.699 is closer to 50 than either 101.700 or 101.098 . Therefore, $\log 50=1.699$, to three decimals. Tables are available giving the logarithm of any number to five decimals, but there is no advantage in the calculations which follow: in this article to using logarithms with more than three decimals.

Certain properties of the logarithm should be kept in mind in the discussion which follows. First, the larger the number the larger its logarithm. Second, as $\boldsymbol{n}$ increases, its logarithm increases more and more slowly, so that $n$ may become very large while log $n$ remains quite small. Thus if $n=1,000,000, \log n$ is still only 6 . Third, the sum of the logs of two numbers is equal to the log of their product.

25. For a discussion of the difference in rate of increase between the logarithmic and power functions see 1 Courant, DIfFerential aNd INTEGral Calculous 190.93 (1937). 
is some insight to be gained by considering again, in an entirely different way, the problem of measuring competition in terms of the number and sizes of firms.

\section{A "Permutations" Derivation}

We assume that the fear of losing customers, or the hope of gaining them, is a principal motivation for competitive behavior. Where the expectation of customer change is high, firms tend to engage in those activities which are called competitive. Assuming generally rational management of firms, these expectations ought to be related to the probabilities that such customer transfers will occur. A mathematical depiction of these probabilities which takes into account all relevant factors is of course vastly beyond the reach of present econometrical and mathematical sciences. The Supreme Court, however, by focusing on the number and sizes of firms, has already suggested the limits of our inquiry. It would be consistent with the bounds of legal relevancy to derive a mathematical expression which describes, at least in a general way, the probabilities of gaining or losing customers as a function of the number and sizes of firms in a market. This suggests that the probability of customer loss (or gain) measured on this basis could be used as a measure of competition. ${ }^{26}$

It is a basic theorem of mathematical probability that the chance of the occurrence of an event which can happen with equal probability in different ways is equal to the probability of its happening in one way times the number of ways in which it can occur. The more such ways the more likely the event becomes. The probability of tossing heads with a coin on both of two trials is half the probability of tossing heads only once in two trials because the first event can only occur in one way (heads on both tosses) while the second event can occur in two ways (heads on either the first or second toss).

A similar principle can be applied to firms and customers. If there are only two competing firms in an industry and only two customers, one for each firm, each firm can lose a customer in only one way and that is by transfer of its customer to the other firm. On the other hand, as the number of firms and customers increases, the number of different ways customers can transfer also increases. If other things are

26. The use of methods drawn from the mathematical theory of probabilities is not unknown in connection with the analysis of measures of concentration. See, e.g., State* ment of Professor Leonard W. Weis, Hearings Before the Subcommittee on Antitrtist and Monopoly of the Senate Judiciary Committee, 89th Cong., 1st Sess., pt. 2, at 728 (1965). 
equal, it seems reasonable to assign a greater probability of customer transfer to a market where such changes can occur in a larger number of ways. This suggests that competition be measured as a function of the number of possible customer transfers. ${ }^{27}$

A customer transfer can be defined most generally as a transfer of any number of customers from any number of firms to any number of firms. A transfer might involve all or part of a single customer's business and two firms or many customers and firms. Not all transfers are equally probable. The loss by the leading firm of all its customers is a possibility too remote to influence behavior. On the other hand, transfers which result in not more than minor changes in firm standing are much more probable. If there is some degree of market share stability it is arguable that the most probable transfers will be permutations-i.e., those transfers which leave market shares unchanged. An exchange of customers by two firms would be a permutation if each firm gained the same number of customers it lost (within some selected period of time). Since permutations are highly probable, we propose to use the class of permutations as representative of the entire class of transfers. In relying on the class of permutations, we are in effect using the number of ways a market can be churned around within a given spectrum of firm sizes. It is our premise that the greater the number of such ways the greater the possibility of competitive behavior.

Obviously the validity of this derivation depends upon the assumption that customers (or separable units in which purchases are made) are either roughly equal in size, or, if different in size, are randomly distributed among all firms. While this will not always be true, it will be approximately true in a sufficient number of instances-e.g., all retail store cases-to warrant the derivation.

In deriving the formula we begin with a simple example. Assume a market with only two firms and four customers. In the first situation firm $A$ has three of the customers and firm $B$ has the fourth. How many different permutations of customers are there which will preserve the three-to-one ratio? The answer is four-the one with which we started and the three resulting from the exchange by firm $A$ of any one of its customers with firm $B$ 's single customer. Suppose now the customers are split evenly between $A$ and $B$. The number of possible permutations is then six: the one with which we started and five addi-

. 27. Evidence of customer transfer has been introduced in the merger cases. See, e.g., Brief for Appellees at 65, United States v. Aluminum Co. of America, 377 U.S. 271 (1964). 
tional permutations resulting from the exchange by firm $A$ of both its customers for both of firm $B$ 's customers; or the exchange by firm $A$ of each of its customers with one or the other of $B$ 's customers. The number of permutations thus rises as the market becomes more evenly divided. This is what we would expect if the number of permutations were a valid measure of the degree of competitive activity.

We turn now to the more general case. If there are $n$ firms in an industry and the first firm has $a_{1}$ customers, the second firm $a_{2}$ customers, etc., the problem is to determine how many different ways these customers may be distributed among all the firms in the market. If the customers of the firms are arranged in a line, the customers of firm $a_{1}$ first, firm $a_{2}$ second, and so on, our question becomes: how many different ways can we arrange the customers on the line? The answer is, by a well-known formula, that if there are $N$ distinguishable customers the number of different arrangements is the product $(N)$ $(N-1)(N-2) \ldots$ (1) which is abbreviated with the symbol $N !$ (" $N$ factorial"). Since the total number of customers in our example is $a_{1}+a_{2}+a_{3} \ldots+a_{n}$ the number of different permutations is $\left(a_{1}+a_{2}+a_{3} \ldots+a_{n}\right) !$ Not all these permutations "count" however. Every one involving solely a permutation of the customers of a single firm is irrelevant. For each firm the number of such permutations is (by the same formula) al Consequently, the total number of permutations $($ Perm $)$ involving intercompany exchanges is: ${ }^{28}$

$$
\text { Perm }=\frac{\left(a_{1}+a_{2}+a_{3} \ldots+a_{n}\right) !}{a_{1} ! a_{2} ! a_{3} ! \ldots a_{n} !}
$$

The number of permutations is thus a function both of the total number of customers in a market and their distribution among the competing firms. In most cases involving horizontal mergers the number of customers is extremely large, so large in fact that the effect on the degree of competition of a change in the number of customers is usually ignored. The only changes considered are those involving the number and relative sizes of firms. Our measure then should be cast in terms which permit us to reflect either of these changes without also reflecting changes in the total number of customers. In addition, the number of permutations must be converted into the form of a translation into equal-firm markets.

28. Derivations of $\mathrm{NI}$ and this expression appear in HOEL, INTROduction to STATISTICS 17 (1965) and in Finkelstein, The Application of Statistical Decision Theory to thc Jury Discrimination Cases, 80 HARv. L. REv. 338, 355 n.60 (1966). 
To accomplish both these purposes let $N=$ the total number of customers and $1 / n_{1}=$ the fractional share of the first firm; $1 / n_{2}=$ the fractional share of the second firm, and so forth. Since $a_{1}+a_{2}+a_{3}+$ $\ldots+a_{n}=N$ and $N / n_{1}=a_{1}$, etc. the expression previously derived becomes by substitution:

$$
\text { Perm }=\frac{N !}{\left(N / n_{1}\right) !\left(N / n_{2}\right) !\left(N / n_{3}\right) ! \ldots\left(N / n_{n}\right) !}
$$

When $N$ (or any other number for that matter) is large there is an approximation for its factorial known as Stirling's approximation which is: ${ }^{29}$

$$
N ! \approx \frac{N^{N}}{e^{N}}
$$

Substituting this approximation for the factorials in the expression for Perm above and simplifying the result yields:

$$
\text { Perm } \approx\left[n_{1}^{1 / n_{1}} n_{2}^{1 / n_{2}} n_{3}^{1 / n_{3}} \ldots n_{n}^{1 / n_{n}}\right]^{3}
$$

If all firms are equal then:

$$
P e r m \approx n^{N}
$$

The number of permutations is thus a function both of the $n_{i}$ and $N$. To eliminate this dependence on $N$ and to set our measure equal to $n$ for equal firm markets we let Perm $=P^{*}$. We then have:

$$
\begin{aligned}
P^{N} & \approx\left[n_{1}^{1 / n_{1}} n_{2^{1 / n_{2}}} n_{3^{1 / n_{3}}} \ldots n_{n}^{1 / n_{n}}\right]^{2 \pi} \\
P & \approx n_{1}^{1 / n_{1}} n_{2}^{1 / n_{2}} n_{3}^{1 / n_{3}} \ldots n_{n^{1 / n_{n}}}
\end{aligned}
$$

This meets our requirements. $P$ is dependent solely on the number and relative sizes of firms and is equal to $n$ when all firms are equal in size. ${ }^{30}$ Comparing the right hand of the above expression with the expression previously obtained for $C$ we have the result that the "permutations measure" which satisfies these requirements is identical to the "competitive activities" measure previously derived. $P=C$.

\section{A "Probabilities" Derivation}

There is a third, perhaps deeper approach to the problems we have been exploring. Here, we consider again the stability of customer-firm

29. A derivation of Stirling's approximation appears in CouRAst, op. cit. supra note 25 , at 361 .

30. The entire chain of this manipulation, involving permutations, factorials, Stirling's formula, and the elimination of the exponent $N$ is directy analogous to the fundamental argument in the statistical theory of gases. Mathematical details may be found in the introductory chapters of any textbook on statistial mechanics. See, e.g., Ter haAr, Elenients of Statistical Mechanics 22 (1954). 
allegiances, but this time seek to determine the probability that, given a particular distribution of customers among firms, no firm will lose a customer to any other firm. ${ }^{31}$

It is assumed that there is a probability that a firm in a market will not lose a particular customer; this probability may be denoted as $q_{1}$. If this firm has $a_{1}$ customers and if we assume further that customers come and go independently then the total probability that this firm will not lose any customers is $q_{1}{ }^{a_{1}}$. Similarly, the probability (Prob) that no firm in the market will lose any customers is:

$$
\text { Prob }=q_{1}^{a_{1}} q_{2}^{a_{2}} q_{3}^{a_{3}} \ldots q_{n}^{a_{n}}
$$

We now confront the problem of determining the probabilities $q_{k}$. Assume for a moment that the values $q_{i}$ are given and we wish to determine what distribution of numbers of customers among the firms is most likely to be observed. It can be shown, using calculus, that the most likely distribution occurs when the $a_{i}$ are such that $q_{i}=a_{i} / N$ where $N$ is the total number of customers. In words: the most likely distribution is that in which each firm has the same fraction of the total number of customers as it has probability of holding a single customer. This is not unreasonable. If, for example, a firm has a 50 per cent chance of holding each customer, that firm is most likely to hold 50 per cent of the total number of customers.

In our problem the $q_{i}$ are not known but the $a_{i}$ are. Since we have found that the most likely distribution occurs when the $a_{i}$ are proportional to the $q_{i}$, it follows that if the $a_{t}$ are given, the most likely situation is that the $q_{6}$ will be proportional to the given $a_{6}$. Thus, $q_{i}=a_{i} / N$.

Let $1 / n_{1}$ be the fraction of the market held by the first firm, etc. Then $a_{1}=N / n_{1}$, etc., as before, and $q_{1}=1 / n_{1}$ by virtue of the argument given above. Substituting these terms in the expression for Prob above we have:

$$
\begin{aligned}
\text { Prob } & =\left[\left(1 / n_{1}\right)^{1 / n_{1}}\left(1 / n_{2}\right)^{1 / n_{2}}\left(1 / n_{3}\right)^{1 / n_{3}} \ldots\left(1 / n_{n}\right)^{1 / n_{n}}\right]^{N} \\
& =\frac{1}{\left[n_{1}^{1 / n_{1}} n_{2}^{1 / n_{2}} n_{3}^{1 / n_{3}} \ldots n_{n}^{1 / n_{n}}\right]^{N /}}
\end{aligned}
$$

The smaller the probability that no customer will shift firm allegiance the greater the level of competitive activity. Thus as Prob decreases competition should increase. This suggests that the "probabilities" measure of concentration, which we denote $Q$, should be theory of gases. See TER HAAR, op. cit. supra note 30. 
constructed from the inverse of Prob so that $Q$ will increase with increasing competition. At the same time, for reasons already discussed in connection with the permutations derivation, we take the $N$ th root to eliminate the variable of the number of customers. Thus:

$$
\begin{aligned}
Q & =(1 / \text { Prob })^{1 / N} \\
& =n_{1}^{1 / n_{1}} n_{2}^{1 / n_{2}} n_{3}^{1 / n_{3}} \ldots n_{n^{1 / n_{n}}}
\end{aligned}
$$

The probabilities derivation thus leads to the same result as the competitive activities and permutations derivations.

Although economic theory is not adequate to establish the validity of any measure beyond question, theoretical arguments can lend plausibility to our choices; it is for this reason that we have given three different theoretical derivations for the entropy measure. We now consider whether the entropy measure leads to any probably wrong results such as we found in examining the concentration ratio and other measures.

\section{Characteristics of the Entropy Measure}

In order to demonstrate the characteristics of the entropy measure as applied to horizontal mergers, we consider the same type of problem considered earlier for the concentration ratios-the successive acquisition by a predator firm of its competitors. We imagine a market with 100 equal firms. $C$ for this market is 100 . After the predator has acquired 5 firms, there are 95 left; the predator with 6 per cent and 94 others with I per cent each. For this market $C=89.8$. When the next 5 firms are acquired leaving a market with 90 firms, the predator has Il per cent of the market and there are 89 others with 1 per cent each: $C=76.8$. The absolute decline in $C$ as a result of the first 5 acquisitions was 10.2. Its absolute decline after the second 5 acquisitions was 13.0. Since the numbers of firms were reduced there was an even larger percentage decline. As the process continues, the absolute decline caused by the acquisition of 5 firms diminishes, because monopoly conditions are being approached, but the percentage decline continues to grow. Thus when the predator firm controls 51 per cent of the market, $C=13.5$ and when it controls 56 per cent, $C=10.5$. This is an absolute decline of only 3.0 but a percentage decline of about 29 per cent. These results seem more closely related to the probable changes in competition than the changes in the concentration ratio which, it may be recalled, showed identical absolute increases and diminished percentage increases as the process continued. 
The entropy measure declines as the result of an acquisition because the market shares of the merging firms are combined into a single firm. If two 10 per cent firms merge, their contribution to $f(C)$ declines from $2 / 10 \log (10)$ to $1 / 5 \log (5)$. Since $\log (5)$ is less than $\log (10)$ we have in effect said that the total degree of competitive activity of two 10 per cent firms is greater than the total degree of such activity on the part of a single 20 per cent firm. This method of registering a change in com* petition resulting from a merger indicates that there is no problem here of comparability or of uniqueness of results such as we faced in dealing with concentration ratios. The effect of every horizontal merger is measured in exactly the same way, and each possible combination of percentages of the merging firms yields a quantitative reduction in the measure. The so-called "defensive merger" which improves com. petition is thus not recognized but must be proved as a special case. This seems consistent with judicial treatment of this defense. ${ }^{32}$

As applied to trends in horizontal concentration the entropy measure avoids the arbitrary determinations which characterized the concentration ratios. The measure takes into account both the number of firms and the percentages of market held by each firm; none are excluded from consideration. The result is that if the leading firms hold a given total percentage of market and the number of firms dividing the remainder increases, the measure will not remain fixed as in the case of the concentration ratio but will increase reflecting the more competitive situation.

In extreme cases this will lead to results which may at first seem paradoxical. Assume for example a market divided between a 90 per cent and a 10 per cent firm. The contribution of the 10 per cent firm to the measure $f(C)$ is $1 / 10 \log (10)$. If the 10 per cent firm divides into two 5 per cent firms the total contribution of the 5 per cent firms becomes $1 / 10 \log (20)$. Repeating the splitting process so that four firms share $1 / 10$ of the market raises the total contribution of the four firms to $1 / 10 \log (40)$. In general if $n$ firms account for $1 / 10$ th of the market, their contribution to $f(C)$ is $1 / 10 \log (10 n)$. As $n$ increases the value of this expression increases without limit and, as a result, so does the value of $f(C)$. Thus even in a market dominated by a 90 per cent firm, the entropy measure may still show a highly competitive market provided the remaining 10 per cent is divided among a sufficiently large number of firms.

32. United States v. Bethlehem Steel Corp., 168 F. Supp. 576 (S.D.N.Y. 1958). 
Is this a paradoxical result? At first thought it may seem so since it can be argued that a market dominated by a 90 per cent firm should never be treated as highly competitive. This is probably true, but the reason it is so depends on a factual assumption: a firm with less than 1 per cent of market cannot be an effective competitive force and consequently a large group of firms whose share aggregates less than 10 per cent cannot be effective competitors to a 90 per cent firm no matter how large their number. But if very small firms were in fact significant competitors there seems no reason to disregard their contribution to the total degree of competitive activity. Thus there is reason to believe that an increase in their number should indeed increase the total of competitive behavior. The theoretical issue then is not whether small firms should be taken into account, but what weight should be given to them. ${ }^{33}$

It is worthwhile noting that in practical examples the entropy measure does not give impossible results. In our 90 per cent-10 per cent example, if one firm controls 10 per cent then $C=1.15$. If the 10 per cent firm is split up into 1000 equal firms $C$ rises only to approximately 2.5. To bring $C$ up to 5 these 1000 firms would have to become $1,000,000$; to bring $G$ up to 10 they would have to become 10 billion.

The relative insensitivity of $C$ to the presence of very small firms makes the decision about which marginal firms to include less important than when other measures are used. ${ }^{34}$ Nevertheless, other examples might be cited (the facts in Von's perhaps present one of them) where the value of the measure turns on the contribution of large numbers of extremely small firms. In such cases it may be argued that the contribution to the total level of competitive activity of these small firms should be given even less importance than their size would indicate and that the measure overestimates their significance by giving them any weight at all.

It is important to recognize that such a cut-off would introduce an entirely new principle of value, namely, a factor that applied solely to extremely small firms. The contributions of large firms would still be

33. We do not overlook the possibility that in the case depicted in the cxample it may be argued that a single 10 per cent firm might be more willing to take on a 90 per cent leader than would a 1 per cent firm. If this were so it could be argued that there would be less competition and not more if the 10 per cent firm were split into ten 1 per cent firms. But this point of view overlooks the existence of competition among the small firms and is most likely to be true with respect to competition with the leading firm in pathological markets of the type illustrated by the example. For these reasons we treat this possibility as an exception to rather than an attribute of the measure.

34. This problem and the not very satisfactory solution of "truncated" indexes is discussed in Singer, supra note 18 , at 86. 
taken seriously, but the contributions of small firms would be regarded as irrelevant, however much they struggled for a share of the market. It is obviously very difficult to make the judgment which this implies. The critical size would probably have to depend on the nature of the market, and its determination would present problems. These diffculties suggest that the issue of effectiveness of competitive activity must be determined as a factor separate from the entropy measure. In the next section we consider briefly a measure which avoids an arbitrary cut-off by treating the competitive activity of small firms as less significant than large ones and thus providing a "smooth" limit to the contribution of smaller firms.

In applying the entropy measure to vertical integrations (either by contract or merger) it is useful to consider the factor $1 / n$ as representing the extent of competitive activities of the firm in question and $\log$ $(n)$ as representing the degree of such activities. Thus for a firm which controls half the customers in a market, $1 / 2$ represents the proportion of customers affected by its competitive activities and log (2) represents the degree or rate of such activities.

To the extent that a firm absorbs its customers by merger or ties them with requirements contracts, competing firms find a segment of the market shielded from them. Thus, if a firm controlling half a market acquires $1 / 2$ its customers, the firm's segment of market still open to competitors would decline from $1 / 2$ to $1 / 4$. To reflect this clo. sure, we adopt the rule that when vertical mergers or requirements contracts are involved, the factor $1 / n$ now represents the proportion of the firm's free customers to the total number of customers in the market, while the factor $\log n$ continues to represent the degree or rate of competitive activity of the tying firm. (Since $1 / n$ and $\log n$ may now vary independently, it is no longer technically correct to write them both in terms of $n$ because this implies a false relation between them; we continue to do so, however, in order to avoid changing the form of the entropy measure.)

A reduction in the proportion of the market which remains free is not, however, the only anticompetitive consequence of vertical integration. Another possibility is that as a firm ties its customers and assures itself a market vis-à-vis these customers, the impetus for competitive activity in the free sector should diminish at least to some extent. Thus, when applying the entropy measure to vertical integrations, $\log n$ should be replaced by a function which decreases in value as integration increases. But what are the limits to the decrease? When 
a firm ties all its customers should it be viewed as engaging in no competitive activities and thus the replacement function equals zero? Factually of course this would not be true since most "customers" in these vertical acquisitions are distributors or processors who must compete with distributors or processors of other firms. Even a firm which has tied all of its distributor-customers must still act competitively if they are to receive goods which can compete in the market. The level of that activity will depend on a variety of factors relating to the imperfections of the market on the distributor level.

These uncertainties deepen if we attempt to define the full shape of the curve by which the replacement function should diminish as vertical integration increases. In most situations, firms fight hard even for the last percentage points of market. For this reason the decline in the replacement function should be negligible until a very large percentage of the market is tied. Since most integrations are not even substantially complete, and since it is difficult to postulate how the replacement function should decrease, we ignore this effect. It is thus assumed that a firm which engages in a vertical integration program will not change its level of competitive activities-although the entropy measure will decline because, in appropriate cases, the effect of such activities will reach only the free customers. In considering vertical mergers, we thus derive the two factors $1 / n$ and $\log n$ from two different values of $n$. In evaluating $1 / n$ we limit the market share of the firm to its free customers; in evaluating $\log n$ we include all a firm's customers.

This conception is also consistent with the probability measure $Q$. A customer which is tied to a firm has probability 1 of not transferring to another firm. To the extent customers are tied, $Q$ is changed proportionately in the way indicated.

Vertical integration always produces a decline in the entropy measure. If there are nine equal firms in a market and one firm ties half its customers the measure declines from 9 to approximately 8.7. If one firm ties all its customers the measure declines from 9 to 8.5 . This is greater than $C$ for an eight-firm market, a result which is consistent with the fact that the remaining firms would engage in a higher level of competitive activity to prevent depredations by the firm whose customers are completely tied. If each firm ties half its customers the measure declines from 9 to 3 . This may seem a large change, but it should be recalled that integration this extensive would be extremely unusual and that the percentage foreclosure test used by the Court would itself show at least a $\mathbf{5 0}$ per cent reduction on these facts. 
IV.

Two important assumptions made in deriving the entropy measure were that (1) the level of a firm's competitive activity is a function solely of its size-this led to the form of $f(c)$ as a sum, and (2) small firms should count in the sense that the measure should show an increase without limit (although at a decreasing rate) as the number of such firms increased-this led to the choice of $\log n$. We found support for these assumptions because the same results were also produced by independent derivations. And we suggested that the second assumption might be necessary because of the difficulties in determining a cutoff point after which firms less than a certain size would no longer be deemed to contribute to competition. We recognize, however, that the considerations which led to and support these choices do not eliminate other possibilities and for this reason we consider briefly alternatives to each.

An alternative to the first assumption is to assume that the level of a firm's competitive activity is determined not by its size, independent of the market, but by its place in the market independent of its size. The simplest way of doing this is to replace $f(n)$ by the rank of the firm in question. The largest firm has rank 1, the next rank 2, and so forth. If two firms are equal in size, they must nonetheless be assigned successive ranks. The rank of each firm is multiplied by its percentage share of market and the products added as in the entropy measure. We then double the grand total and subtract 1 to obtain $L$, the ordinal measure of concentration. The purpose of the doubling and subtraction is to provide that if all firms are equal and there are $n$ firms then $L=n$ as in the case of the entropy measure.

Thus if there are five equal firms, their ranks, market shares and ordinal products are:

\begin{tabular}{ccc}
\hline Rank & Share & $\begin{array}{c}\text { Ordinal } \\
\text { Product }\end{array}$ \\
\hline 1 & 0.20 & 0.20 \\
2 & 0.20 & 0.40 \\
3 & 0.20 & 0.60 \\
4 & 0.20 & 0.80 \\
5 & 0.20 & 1.00 \\
& & $\overline{3.00}$ \\
\hline
\end{tabular}

$L=3.00 \times 2-1=5$

If two of these firms merge, then: 


\begin{tabular}{ccc}
\hline Rank & Share & $\begin{array}{c}\text { Ordinal } \\
\text { Product }\end{array}$ \\
\hline 1 & 0.40 & 0.40 \\
2 & 0.20 & 0.40 \\
3 & 0.20 & 0.60 \\
4 & 0.20 & 0.80 \\
& & 2.20 \\
\hline
\end{tabular}

$L=2.20 \times 2-1=3.4$

A little algebra shows that the ordinal measure is closely related to the Lorenz curve. In fact, $L$ is just twice the area under the curve when the vertical scale is relative and the horizontal scale is absolute. That is, the total height of the graph is taken as one unit, regardless of the actual market size, but the total width is taken as equal to the number of firms, so that each firm contributes one unit of width..$^{35}$

If $G$ is the value of the Gini coefficient measured in the usual way and $n$ is the number of firms, then $L=(1-G) n$. If one wishes to base a measure of economic concentration on the Lorenz curve, then $L$, rather than $G$, is the appropriate measure. $L$ measures both absoIute and relative concentration ( $G$ measures only changes in relative concentration) and in addition has the desirable property of changing only slightly as a result of the appearance or disappearance of an extremely small firm. ( $G$ changes dramatically in that circumstance.)

Although the ordinal measure is a better index of market concentration than the Gini coefficient, there is no reason to prefer it to the entropy measure and some important reasons not to. First, the entropy measure may be supported by the theoretical arguments we have given; there are no such arguments to sustain the ordinal measure. The only theoretical justification the ordinal measure may have is that it is related to the Lorenz curve which is familiar to economists. Second, although the ordinal measure may seem easier to compute than the entropy measure since the rank of a firm is more easily found than the logarithm of its size, it is actually more difficult. For the labor of multiplication in computing $C$ can be circumvented by using a readymade table of $1 / n \log (n)$, whereas no readymade table for computing $L$ is possible since each firm's contribution depends on two quantities, its

35. The area under the Lorenz curve can be divided into horizontal slabs, each bounded on the left by a diagonal element of the curve. If the firm that corresponds to this diagonal element has a rank $a$ and market share $x$, then the slab has vertical thickness $x$ and horizontal length varying from $a$ to $a-1$ at the lop. Therefore the area of the slab is $(a-1 / 2) x$. The total area under the graph is $\Sigma(a-1 / 2) x=\Sigma a x-$ $1 / 2 \Sigma x=\Sigma a x-1 / 2$. Twice the area is $2 \Sigma(a x)-1$, which by definition is equal to $\Sigma$. 
rank and size, which can vary separately. Third, the ordinal measure appears to give excessive weight to small firms. In the 90 per cent-10 per cent example given earlier we have $L=1.10$ when the 10 per cent firm is undivided; $L=6.00$ when the 10 per cent firm splits into 99 equal firms; and $L=51.0$ when these 99 become 999 . According to the ordinal measure it is thus possible to have a low degree of concentration in a market dominated by a 90 per cent firm. As we have seen, this is not practically possible if the entropy measure is used.

The second assumption is that the degree of competition increases without limits as the number of small firms increases. An alternative to this is a measure which never increases beyond a fixed limit, no matter how large $n$ becomes for a segment of the market. The simplest such function which satisfies the requirement $f(1)=0$ and which also increases at a decreasing rate as $n$ increases is:

$$
f(n)=1-1 / n
$$

This function leads to the remainder measure, so called because the function $f(n)$ for each firm is just the fraction of the market which it does not control. Denoting this measure by $R$, we have:

$$
\begin{aligned}
f(R)= & \Sigma 1 / n f(n) \\
& \Sigma 1 / n(1-1 / n) \\
& \Sigma 1 / n-1 / n^{2}
\end{aligned}
$$

Since $\Sigma 1 / n=1$ this yields:

$$
f(R)=1-\Sigma 1 / n^{2}
$$

Since $f(n)=1-1 / n$ then $f(R)=1-1 / R$. Substituting in the expression for $f(R)$ we have:

$$
\begin{aligned}
1-1 / R & =1-\Sigma 1 / n^{2} \\
1 / R & =\Sigma 1 / n^{2}
\end{aligned}
$$

$R$ is thus easy to compute. If all the firms are equal then $1 / R=$ $(n)\left(1 / n^{2}\right)=1 / n$ or $R=n$ as we required. If there are four firms in the market with the sizes $40 \%, 20 \%, 20 \%, 20 \%$, then $1 / R=0.40^{2}+0.20^{2}$ $+0.20^{2}+0.20^{2}=0.28 ; R=3.57$. (This may be compared with $C=$ 3.78 and $L=3.40$.)

Returning to the small firm problem which was our reason for considering $R$, in the 90 per cent-10 per cent example considered earlier $R=1 / 0.82=1.22$ if there are only two firms. If the 10 per cent firm is split up into many small firms $R$ never grows larger than $1 / 0.81=$ 1.23, no matter how many small firms there are. $R$ is thus extremely insensitive to small firms. This is a major objection to its use as a measure of trends in concentration. (Since $R$ is the reciprocal of the 
Herfindahl index, see p. 688 supra, the objections to $R$ would also apply to the Herfindahl index.)

When all firms are equal in size, the measures $C, L$ and $R$ all equal the number of firms. The concentration ratio is usually not expressed in this way, although it obviously can be, and the remaining measures were defined to produce this result. When firms differ in size only slightly the measures differ only slightly. Usually $C$ is the largest and $L$ the smallest. But as the number of small firms starts to grow the situation changes. Then in order of increasing sensitivity to small firms we have: the concentration ratio which remains unchanged; the remainder measure $R$ which increases but never by more than a small fixed amount; the entropy measure $C$ which may increase indefinitely in theory but only a little in practice; and lastly the ordinal measure $L$ which may become very large both in theory and practice.

In the applications which follow we consider principally the entropy measure since it is supported by theoretical considerations which the others lack and since the values produced do not lead to results which are obviously erroneous. But these other measures also merit consideration and we shall give some comparative calculations for them in footnotes.

V.

In applying the entropy measure it is not unusual to find that the record affords an inadequate basis for an exact computation. Frequently basic statistical information is incomplete even in an antitrust record of thousands of pages. Our method of dealing with such gaps is to assume a state of facts adverse to the Government since it carries the burden of proof. We select a few examples to demonstrate the method of computation and the information which the entropy measure makes available.

In the Alcoa case, the Court found that two lines of commerce could be differentiated: insulated aluminum conductors and a broader line of insulated and bare aluminum conductors. ${ }^{36}$ The significance of the merger was not the same in these lines, and this difference turns out to be meaningful for the choice of line problem.

Prior to the merger, the total contribution by Alcoa and Rome to $f(C)$ in the broader line was 0.179 . After the merger, Alcoa's contribution became 0.156 decreasing $f(C)$ from 0.891 to 0.868 . Thus $C$ de-

36. United States v. Aluminum Co. of America, 377 U.S. 271 (1964). 
clined from 7.7 to 7.35 as a result of the merger. ${ }^{37}$ This indicates a rather small increase in a highly concentrated line of commerce.

In the line of insulated aluminum conductors, the total contribution of Alcoa and Rome to $f(C)$ prior to the merger was 0.171. After the merger Alcoa's contribution became 0.128 , decreasing $f(C)$ from 1.025 to 0.982 . Thus $C$ declined from 10.6 to 9.6 as a result of the merger. $^{38}$

To summarize:

THE ENTROPY MEASURE

\begin{tabular}{lcc}
\hline & Pre-Merger & Post-Merger \\
\hline Insulated \& Bare Aluminum & 7.7 & 7.35 \\
Insulated Aluminum & 10.6 & 9.6 \\
\hline
\end{tabular}

37. In 1958, shortly before the merger, the shares of the firms in the aluminum conductor line and the corresponding values of $1 / n f(n)$ were as follows:

ALUMINUM CONDUCTOR (BARE \& INSULATED)

\begin{tabular}{lcc}
\hline \multicolumn{1}{c}{ Firm } & 1958 percentage share & $1 / n f(n)$ \\
\hline Alcoa & 27.8 & 0.155 \\
Rome & 1.3 & 0.025 \\
Anaconda & 15.8 & 0.127 \\
Kaiser & 23.1 & 0.147 \\
Bristol & 4.5 & 0.061 \\
Reynolds & 10.4 & 0.102 \\
General Cable & 6.0 & 0.078 \\
Essex Wire & 4.5 & 0.061 \\
Hendrix & 0.2 & 0.005 \\
Southwire & 2.3 & 0.038 \\
Nehring & 0.5 & 0.012 \\
Walker & 0.1 & 0.003 \\
Western & 0.1 & 0.003 \\
8 Firms & 3.3 & 0.079 \\
21 Firms & 99.9 & 0.891 \\
\hline
\end{tabular}

Plaintiff's Exhibit 434, Record on Appeal at 2713-14.

38. In the line of insulated aluminum conductor the figures are as follows:

ALUMINUM CABLE (INSULATED)

\begin{tabular}{lcc}
\hline \multicolumn{1}{c}{ Firm } & 1958 percentage share & $1 / n f(n)$ \\
\hline Alcoa & 11.6 & 0.109 \\
Rome & 4.7 & 0.062 \\
Kaiser & 26.8 & 0.153 \\
Anaconda & 16.9 & 0.131 \\
General Cable & 9.5 & 0.097 \\
Essex & 6.1 & 0.074 \\
Olin Mathieson & 5.3 & 0.068 \\
Reynolds & 4.8 & 0.068 \\
Southwire & 2.5 & 0.040 \\
Firms 10-19 & 11.8 & 0.228 \\
19 Firms & 100.0 & 1.025 \\
\hline
\end{tabular}

Plaintiff's Exhibit 436, Record on Appeal at 2517-18. 
We are now in a position to compare the effects of merger in the two lines of commerce in a way which was not open to the litigants. The entropy measure indicates that the wider line of aluminum conductor was more concentrated than the line of insulated aluminum conductor, but that both lines were highly concentrated. It also shows that the merger was probably more significant both absolutely and proportionately in the insulated line than in the wider line. This suggests that the case could and should have been disposed of solely on the basis of the effect on the insulated line. The Court's reliance on the dubious broader line was unnecessary in light of the finding of the entropy measure that the merger in the insulated line was probably of greater significance. ${ }^{39}$

Manufacturers Hanoverto illustrates the use of the entropy measure in resolving problems of stare decisis. The district court had held that the decision in Philadelphia Bank afforded no basis for concluding that the Manufacturers Hanover merger should also be held prima facie unlawful. The court gave two reasons for its conclusion: first, the share of the merged firms was 30 per cent in Philadelphia Bank and only 14 per cent in Manufacturers Hanovor, and second, if the merger were consummated, the merging banks in Philadelphia would have a significantly larger share of market than their nearest competitors, while in Manufacturers Hanover the merged banks would have been only third in the New York metropolitan area.

These considerations are obviously relevant but not exhaustive. The entropy measure provides a more systematic basis for comparison.

Prior to the merger in Philadelphia Bank, $f(C)=1.049 ; C=12.73$. The merger of Philadelphia National Bank and Girard Trust Company reduced their contribution to $f(C)$ by 0.105 . After the merger

39. We have applied the ordinal measure $L$ and the remainder measure $\boldsymbol{R}$ to this case. The results are shown in this table.

\begin{tabular}{|c|c|c|c|c|c|c|}
\hline \multirow{2}{*}{$\begin{array}{c}\text { Measure } \\
\text { Line of Commerce }\end{array}$} & \multicolumn{2}{|c|}{$c$} & \multicolumn{2}{|c|}{$\boldsymbol{L}$} & \multicolumn{2}{|c|}{$R$} \\
\hline & Broad & Narrow & Broad & Narrow & Broad & Narrow \\
\hline $\begin{array}{l}\text { Before Merger } \\
\text { After Merger } \\
\text { Absolute Decrease } \\
\text { Per Cent Decrease }\end{array}$ & $\begin{array}{l}7.7 \\
7.35 \\
0.35 \\
4.6 \%\end{array}$ & $\begin{array}{l}10.6 \\
9.6 \\
1.0 \\
9.4 \%\end{array}$ & $\begin{array}{l}5.846 \\
5.558 \\
0.288 \\
4.9 \%\end{array}$ & $\begin{array}{l}8.168 \\
7.412 \\
0.756 \\
9.2 \%\end{array}$ & $\begin{array}{l}5.72 \\
5.50 \\
0.22 \\
3.8 \%\end{array}$ & $\begin{array}{l}7.38 \\
6.84 \\
0.54 \\
7.3 \%\end{array}$ \\
\hline
\end{tabular}

The significance was "probably" greater in the narrow line because the cxact meaning of the change in $C$ poses an economic question which the mersure does not purport to answer.

40. See note 8 supra. 
$C=8.79$. Thus, as a result of the merger, $C$ declined from 12.73 to 8.79 .41

Prior to the merger in Manufacturers Hanover, $f(C)=1.140 ; C=$ 13.8. The merger of Manufacturers Trust Co. and The Hanover Bank reduced their contribution to $f(C)$ by 0.044 . After the merger $f(C)=$ 1.096; $C=12.9$. Thus, as a result of the merger, $C$ declined from 13.8 to 12.9 .42

41. The statistics in United States v. Philadelphia National Bank, 374 U.S. 821 (1963), are as follows:

DEPOSITS IN COMMERCIAL BANKS PHILADELPHIA METROPOLITAN AREA

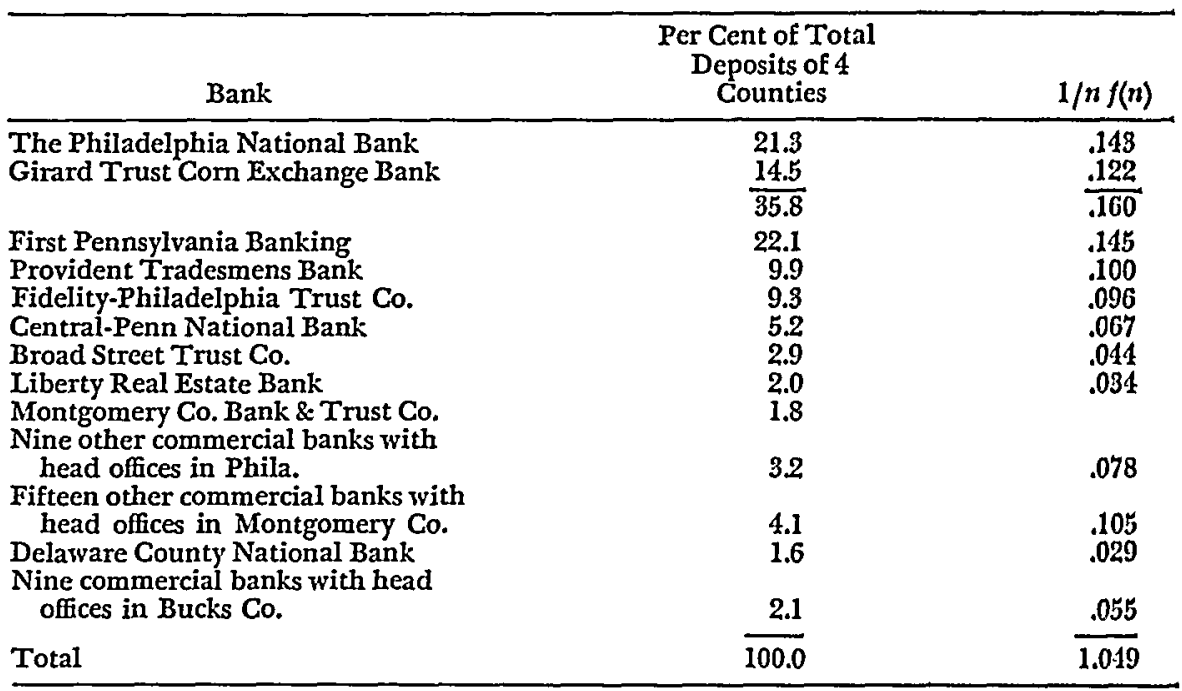

See Table 2, Record on Appeal at 2349. We have used the more elaborate data from the record rather than the abbreviated data cited by the court.

42. The statistics in Manufacturers Hanover are as follows:

DEPOSITS IN COMMERCIAL BANKS: NEW YORK METROPOLITAN AREA

\begin{tabular}{lcc}
\hline \multicolumn{1}{c}{ Banks Ranked by Size of Assets } & $\begin{array}{c}\text { Per Cent } \\
\text { Total Deposits }\end{array}$ & $1 / n f(n)$ \\
\hline Chase Manhattan Bank & $20.01 \%$ & .140 \\
First National City Bank & 17.59 & .193 \\
Chemical Bank New York Trust Co. & 10.16 & .101 \\
Morgan Guaranty Trust Co. & 9.12 & .095 \\
Manufacturers Trust Co. & 9.24 & .096 \\
Bankers Trust Co. & 7.81 & .089 \\
Irving Trust Co. & 5.38 & .068 \\
Hanover Bank & 4.64 & .062 \\
Franklin National Bank & 1.93 & .033 \\
Marine Midland Trust Co. & 1.81 & .032 \\
Bank of New York & 1.62 & .029 \\
Meadow Brook National Bank & 1.42 & .026 \\
\hline
\end{tabular}

Table continued on page 711 . 
To summarize:

THE ENTROPY MEASURE

\begin{tabular}{lcc}
\hline & Pre-Nerger & Post-Merger \\
\hline Philadelphia National Bank & 12.7 & 8.8 \\
Manufacturers Hanover & 13.8 & 12.9 \\
\hline
\end{tabular}

The entropy measure indicates that the Philadelphia Bank market was slightly more concentrated than the Manufacturers Hanover market and that the merger in Philadelphia Bank appears more significant than in Manufacturers Hanover. These results sustain the Court's conclusion that Manufacturers Hanover cannot be deemed a prima facie case solely on the basis of the decision in Philadelphia Bank.

The facts in the Von's case ${ }^{43}$ can be used to illustrate the application of the entropy measure to trends in concentration. In Von's, the decision apparently depended on two factors: (l) the reduction in the number of firms in the periods prior to and following the merger, and (2) the increase in size of the merging firms.

The Government did not introduce any evidence of the size breakdown of individual firms in 1948, ten years before the merger, but did introduce evidence of percentage shares of groups of firms. Assuming a distribution most favorable to the defendants, namely, that the firms

\section{Continued}

DEPOSITS IN COMMERCIAL BANKS: NETV YORK MIETROPOLITAN AREA

\begin{tabular}{lcc}
\hline Banks Ranked by Size of Assets & $\begin{array}{c}\text { Per Cent } \\
\text { Total Deposits }\end{array}$ & $1 / \boldsymbol{n} f(\boldsymbol{n})$ \\
\hline County Trust Co. & 1.29 & .024 \\
Savings Bank Trust Co. & 0.54 & .012 \\
Empire Trust Co. & 0.52 & .012 \\
Grace National Bank & 0.55 & .012 \\
United States Trust Co. of New York & 0.50 & .012 \\
National Bank of Westchester & 0.57 & .013 \\
Federation Bank \& Trust Co. & 0.53 & .012 \\
Commercial Bank of North America & 0.45 & .012 \\
Sterling National Bank \&. Trust Co. & 0.40 & .009 \\
First National City Trust Co. & 0.32 & .003 \\
Trade Bank \& Trust Co. & 0.30 & .003 \\
Long Island Trust Co. & 0.26 & .007 \\
Subtotal & $\mathbf{9 7 . 0 5 \%}$ & $\mathbf{. 0 9 5}$ \\
Total 48 Remaining Banks & $2.95 \%$ & .095 \\
Total All Banks & $100.00 \%$ & 1.140 \\
\hline
\end{tabular}

43. 384 U.S. 270 (1966). See note 14. 
in each group were equal, for the year $1948, C=985 .{ }^{44}$ The principal contribution was from very small firms. By any standards, this is a highly competitive market.

For the year 1958 the Government put in more detailed statistics. Since in making comparisons it would be misleading to use the more general figures for 1948 and the more specific figures for 1958, we use the more general figures for 1958 as well. ${ }^{45}$ Using these figures, for the

44.

GROCERY FIRMS IN LOS ANGELES-1948

\begin{tabular}{lcc}
\hline Number of Firms & Aggregate Share & $1 / n f(n)$ \\
\hline Firms 1-4 & 25.9 & .308 \\
Firms 5-8 & 7.8 & .136 \\
Firms 9-12 & 5.1 & .183 \\
Firms 19-16 & 2.8 & .060 \\
Firms 17-20 & 2.1 & .048 \\
Firms 21-6221 & $\underline{57.2}$ & $\frac{2.808}{2.093}$ \\
\hline 6221 & $\underline{99.9}$ & \\
\hline
\end{tabular}

See Record on Appeal at 2331.

45.

GROCERY FIRMS IN LOS ANGELES-1958

\begin{tabular}{lcc}
\hline Number of Firms & Aggregate Share & $1 / n f(n)$ \\
\hline Firms 1-4 & 24.4 & 0.296 \\
Firms 5-8 & 16.5 & 0.229 \\
Firms 9-12 & 7.9 & 0.135 \\
Firms 13-16 & 4.6 & 0.089 \\
Firms 17-20 & 3.5 & 0.072 \\
Firms 21-4741 & 43.1 & 1.741 \\
4741 & 100.0 & $\mathbf{2 . 5 6 2}$ \\
\hline
\end{tabular}

See Record at 2324, 2331. The figure for total firms is as of the end of 1960, the only figure available. DETAILED BREAKDOWN: GROCERY FIRMS IN LOS ANGELES-1958

\begin{tabular}{lcc}
\hline \multicolumn{1}{c}{ Firm } & Percentage Share & $1 / n f(n)$ \\
\hline Safeway & $8.0 \%$ & .088 \\
Ralph's & 6.4 & .076 \\
Von's & 4.7 & .062 \\
Market Basket & 4.4 & .060 \\
Thriftimart & 4.4 & .060 \\
Shopping Bag & 4.2 & .058 \\
Food Giant & 3.6 & .052 \\
Alpha Beta & 3.1 & .047 \\
Fox Markets & 2.8 & .043 \\
Mayfair & 2.0 & .034 \\
Firms 11-12 & 5.2 & .082 \\
Firms 13-16 & 4.6 & .089 \\
Firms 17-20 & 3.5 & .072 \\
Firms 21-4741 & 43.1 & $\mathbf{1 . 7 4 1}$ \\
4741 & 100.0 & 2.564 \\
\hline
\end{tabular}

See Record at 2329, 2331.

The result here is, as one would expect, close to the estimate based on the morc general data. The fact that $C$ is larger than if computed on the more general data is due to discrepancies between the general and particular data for 1958. 
year 1958, $C=364$. Although the decline over the decade was evidently substantial, the market, in 1958, was still highly competitive.

In order to determine the effect of the merger it is necessary to compute the shares of the individual firms. This computation, based on the detailed breakdown, shows that before the merger $f(C)=2.564$; $C=367$. The merger of Von's and Shopping Bag reduced $C$ from 367 to 340 equal firms. Thus, both before and after the merger, the market remained highly competitive. By giving significant weight to large numbers of small firms the entropy measure leads to results which do not sustain the Government's claim that the market in Von's had become so highly concentrated that it "was approaching oligopoly." the evidence of the entropy measure is accepted, Von's is an "incipiency" case with a vengeance.47

VI.

By holding that evidence of the number and sizes of firms in a market is sometimes alone sufficient for the Government's case, the Court has assigned a crucial role to such evidence and shifted the battle over the use of statistics in Section 7 proceedings. Judges must now decide not whether to rely solely on statistical evidence, but when to do so. It has been our thesis that the methods presently used to measure economic concentration-principally concentration ratios-are

46. Brief for the United States at 28.

The three measures we have derived yicld very different results when applied to the facts in Don's. From the individual firm sizes we obtain $L=1750$ before the merger and $L=1748$ after; $R=40.4$ before and 34.9 after. The measures differ substantially because they attach different relative importance to lange and small firms. The merger affects only the larger firms, and therefore has little effect on $L$ which is large becuse of the lange total number of firms. But it has a strong effect on $R$, which depends almost exclusircly on the larger firms.

We may compare the effect of this merger with that of an imaginary one in which roughly 400 of the small firms are absorbed by the larger ones. This would also reduce $C$ from 367 to roughly 340 . But $R$ would fall only to 40.0 remaining almost unchnnged. $L$, however, would drop by about 100 . These examples demonstrate that $C$ is intermediate between $L$ and $R$ in its weighting of small firms.

47. United States v. Pabst Brewing Co., 384 U.S. 901 (1960), also appears to be an incipiency case-although less extreme than Von's. The record in Pabst was uniquely complete. It showed the market share percentage of every firm down to 001 per cent for the years 1958 through 1961. Record on Appeal at 170-84. On the basis of these statisties the Court found that the three-year period immediately following the merger had been marked by a continuing trend toward concentration. The calculations of the entropy measure are too long to reproduce here, but they show that in $1958 \mathrm{C}$ declined from 66 to 64 as a result of the merger; and that the trend to concentration relied on by the Court had by 1961 reduced $C$ to 51 . This would appear to be a substantial decline although the market is evidently still highly competitive. For a discussion of Pabst's market share before and after the merger, see note 14 supra. 
not well suited to resolve this and other issues which the Court's rule has made prominent.

In cases arising under the amended Section 7, the Court has repeatedly relied in its analysis of statistics on the results in prior cases. Since comparisons of this sort are a primary analytic tool, the method used to express the degree of concentration should facilitate them. But as we have seen, there are only limited factual situations in which concentration ratios permit valid and adequate comparisons. In Manufacturers Hanover comparison was not possible, while in Von's and Pabst the change in the concentration ratio reflected a particular, and relatively less important, aspect of market changes. Comparability may be improved by relying on a single factor, such as the sizes of the merging firms, but only at the cost of disregarding market data which may be highly relevant. And the use of such artificially limited measures emphasizes the economic unreality of the Court's reliance on statistics.

The lack of comparability is but the prelude to a deeper problem. When comparisons are sought with statistics from other industries, or where stare decisis does not dictate the answer, a court must make a decision concerning the economic significance of the statistics. Since the economic problem is complex, some simplification or reduction is essential. But concentration ratios are of little help in this regard because the reduction they effect is purely statistical. It is because no theory of competitive behavior underlies the concentration ratio that the Court, in the leading Section 7 cases, has been unable to supply a reasoned connection between its economic judgments and the statistical basis on which they rest.

A measure in the form of a translation into equal-firm markets would be better suited to implement the Court's view. A translation measure simplifies the economic problem by making an economic statement: the level of competitive activities of the market under consideration is equivalent to that of a market with a certain number of equal firms. This would seem to be a better form in which to make the ultimate economic judgment, even though the results of the measure cannot determine that judgment. A court must still make a finding concerning the degree of competition to be anticipated for the equivalent equal-firm markets before and after the merger and decide whether the change should be viewed as substantial. But by expressing the statistics in terms of equal-firm markets a court's task may be simplified. It also seems more reasonable to conclude, as the Court has done without 
using this measure, that the greater the change in the equal-firm measure occasioned by a merger the less relevant other economic information becomes, until, finally, the statistical evidence alone is sufficient for a prima facie case. Once the statistics are cast in the form of an economic statement, the role of other economic evidence becomeslogically as well as legally-complementary to this primary evidence.

The foregoing assumes that the translation measure embodies an economic truth. What assurance do we have that a given market has the same degree of competitive activity as a market consisting of $n$ equal firms? The general problem is that economic theory "cannot yet sustain reliable predictions concerning the impact on market behavior of any but the most sweeping mergers." 48 The most that can be said is that if a measure is egregiously twrong, a majority of economists would believe its statements false; but even then there is probably no empirical or theoretical test of these opinions.

The absence of provability is not fatal to the usefulness of a translation measure. Any measure on which comparisons rest depends on some equally unprovable assumptions. The simple decision to consider solely the sizes of the merging firms depends on the unverifiable hypothesis that the rest of the market is irrelevant. So the choice is not whether to use unprovable assumptions, but which ones to use. The answer is that we should test and use those assumptions which lead to a measure useful in form. Of course the assumptions should be economically plausible and should be plainly stated to permit debate and correction.

The assumptions used in deriving the entropy measure have certain arbitrary elements but they seem to us to be within a range of reasonableness and they or some equally unprovable alternatives are necessary to construct any translation measure.

With respect to the "competitive activities" derivation, the choice of the logarithmic functions seems preferable to its rivals, but the choice of $\log n$ over other logarithmic functions is necessarily arbitrary. Log $n$ was chosen because this is the simplest of the log functions and we have no economic basis for a different, more complicated, choice. The log function also turns out to be consistent with the results of other derivations. The independence hypothesis-the assumption that a firm's level of competitive activity is a function solely of its size-was again a choice based on considerations of simplicity. For we know of

48. Bok, Section 7 of the Clayton Act and The Merging of Low and Economics, 74 HARV. L. REv. 226, 244 (1960). 
no way to resolve the complex choices involved in the contrary assump. tion that the rate of competitive activity is dependent on the shape of the entire market, or a part of it.

With respect to the "permutations" derivation, the assumption that customer permutation is a valid measure of competition is undoubtedly novel. The probability of customer transfer would seem related to competitive activity, and permutations are of importance if transfers are considered in terms of their probability. The fact that the number of permutations is inversely proportional to the probability (as we have computed it) that no customer would change allegiance lends support to the use of the number of permutations as a measure of the probability of customer transfer. The "probability" derivation itself rests on the independence hypothesis and on our determination that a firm's probability of holding its customers is most likely to be proportional to its size.

The test of these assumptions cannot be their eternal truth, but whether plausible alternatives can be framed which lead to essentially different results. We have illustrated the testing process by proposing alternatives to the independence hypothesis and the choice of the $\log$ function. These yield results which seem less in accord with economic ideas than the entropy measure. Other choices may yield better results.

The problems of constructing a measure reflect the larger fact that the law has established a test involving economic prediction which in most cases will remain beyond the reach of economic science. These uncertainties will deepen if the Government extends its antitrust en* forcement program to the full range apparently sanctioned by the Court's recent decisions. A more inclusive program of this type will present the enforcing agencies and the courts with much closer questions than those with which they have dealt so far. More than ever, the weaknesses, gaps and inadequacies of economic prediction will reveal the problems inherent in applying the statutory standard. More than ever, the Court will have to take refuge in the fact that Congress was dealing "with probabilities and not certainties" and that "mergers with a probable anti-competitive effect were to be proscribed by this Act."

Even within the permissive standard of probabilities, it is obvious that the entropy measure itself is not an end to the problem of measuring concentration for the Clayton Act any more than a mercator or polar projection is an end to map making. Factors may be addedsuch as the degree of stability of market structure-which would per* 
An Entropy Theory

haps lead to greater refinement. Our purpose has not been to give a complete answer to these problems, but to demonstrate the first result of an approach which seeks to coordinate the problems of measurement with the purposes of the law. 